\title{
Post-deployment Multi-symptom Disorder rehabilitation: An integrated approach to rehabilitation
}

\author{
Michelle A. Bosco ${ }^{a, *}$, Jennifer Murphy ${ }^{\mathrm{a}, \mathrm{b}}$, Walter E. Peters ${ }^{\mathrm{a}, \mathrm{b}}$ and Michael E. Clark ${ }^{\mathrm{a}, \mathrm{b}}$ \\ a James A. Haley Veterans' Hospital, Tampa, FL, USA \\ ${ }^{\mathrm{b}}$ University of South Florida, Tampa, FL, USA
}

Received 29 May 2013

Accepted 6 January 2014

\begin{abstract}
.
BACKGROUND: Veterans and active duty service members returning from Operation New Dawn and those having returned from Operations Iraqi and Enduring Freedom frequently report the presence of overlapping, co-morbid symptom clusters consisting of chronic pain, mild cognitive complaints, and posttraumatic stress symptoms/disorder or mood disturbance. This presentation has been called Post-deployment Multi-symptom Disorder (PMD) and its implications not only impact various functional domains, but have also influenced a system/continuum of care to rise to meet the challenges of treating PMD. This continuum is based on innovation informed by evidence-based therapies, systemic limitations, and a focus on functional improvement rather than diagnostic classification.

OBJECTIVE: The purpose of this paper is to describe the symptomatic, functional and systemic challenges inherent to PMD conceptualization and treatment.

METHOD: The constituent clusters of PMD are defined and exemplified, its functional impact is illustrated, and a continuum of care at a large southeastern Veterans Affairs (VA) hospital offering an interdisciplinary approach to integrated rehabilitation is described. Three case examples are provided that that underscore the importance of vocation for improved behavioral health and quality of life.
\end{abstract}

CONCLUSION: The case examples demonstrate how vocational rehabilitation services are an integral component of PMD treatment.

Keywords: Co-morbid symptomology, chronic pain, posttraumatic stress disorder, behavioral health, rehabilitation

\section{Introduction and background}

Chronic pain and mental health disorders often cooccur $[1,2]$ as reflected in a growing body of literature that documents the frequent co-morbidity of chronic pain and posttraumatic stress disorder (PTSD) [3-7]. Moreover, the elevated prevalence of PTSD in both

* Corresponding author: Michelle A. Bosco, 13000 Bruce B. Downs Blvd (116B), Tampa, FL 33612, USA. Tel.: +1 813972 2000, extension 7452; Fax: +1 813903 2814; E-mail: Michelle.Bosco@ va.gov. civilian (3) and veteran chronic pain populations in the United States [8-12] has been well documented. For returnees from Operation New Dawn (OND) and veterans or service members having returned from recent conflicts Operations Iraqi Freedom and Enduring Freedom (OIF and OEF, respectively), pain continues to be one of the most frequently reported symptoms [13, 14] upon presentation to VA medical sites. Injuries sustained on the battlefield in the current military actions may have proven fatal in prior conflicts; however, advances in medical care far forward in the combat theater combined with advances in protective armor have 
led to increased survival rates [15]. The frequent use of improvised explosive devices (IEDs), landmines, and rocket propelled grenades (RPGs) by insurgent groups in Iraq and Afghanistan highlight the importance of understanding the impact of repeated blast exposure on the human brain, body and emotional well-being. Nonblast injuries resulting from gunshot wounds, shrapnel, vehicular crashes, falls and other physical traumas also contribute to the physical and emotional traumas of war.

Subsequently, many OIF/OEF/OND returnees present to Veterans Affairs (VA) hospitals or clinic settings with a constellation of overlapping and interrelated symptoms consisting of three domains: chronic pain; posttraumatic stress symptoms/disorder (PTS/D) or mood disturbance (e.g., depression; irritability; anger); and mild cognitive complaints that may or may not reflect the persistence of a post-concussive syndrome (PCS) $[4,12,16,17]$. Walker and colleagues [16] have termed this collection of overlapping symptoms Post-deployment Multi-symptom Disorder (PMD) and the constituent factors comprising it are defined as follows. First, chronic pain may be defined as pain lasting greater than 3 months and persisting beyond the healing of the initial injury or disease process [18]. As the chronicity of pain increases, emotional distress, functional implications, and increased utilization of the healthcare system tend to occur $[8,12,19$, 20]. Second, PTSD is defined as the development of re-experiencing phenomena, avoidance behaviors, and hyperarousal symptoms after experiencing or witnessing an extreme traumatic event [21]. The emotional reaction to the event is characterized by horror, intense fear, or helplessness. Trauma-related symptoms persist for at least one month and lead to clinically significant distress and/or impairment in social, occupational, or other functional domains. Third, PCS may be defined as persistent cognitive, emotional and physical complaints following concussion or mild traumatic brain injury (mTBI) [16].

Lew and colleagues [12] found that $42.1 \%$ of OIF/ OEF veterans evaluated at a large northeastern VA medical center presented with a combination of pain, PTSD and PCS, accounting for the largest percentage of combined symptoms within that sample. Those reporting the presence of both pain and PTSD accounted for $16.5 \%$. The literature on those with chronic pain and PTSD indicate the presence of more frequent health problems $[22,23]$ as well as more frequent absenteeism [23] and greater loss of productivity [24]. Furthermore, they evidence greater pain-related dis- ability, higher pain ratings, higher rates of health care service utilization, and increased functional impairment in areas such as sleep quality, relationship strain, physical deconditioning. Walker and colleagues [16] highlight that barriers to successful treatment of PMD reflect not only the complexity of symptom interaction, but the confines of traditional models of care that have failed to meet clinical need and facilitate improved quality of life.

One of the most significant reflections of life satisfaction is the engagement in vocational endeavors such as employment or education. These endeavors are particularly challenging issues for the OIF/OEF/OND population. While the overall unemployment rates for veterans is below the national average of $7.9 \%$, the rate for post-9/11 veterans is approximately $10 \%$ [25]. The disturbing rate for female OIF/OEF Veterans is close to $20 \%$, and for veterans ages $21-24$, the numbers range from $25-35 \%$ [26]. While bills such as the Veterans Opportunity to Work (VOW) and Hire Our Heroes Act of 2011 have been beneficial, there is still a great deal of adjustment-related anxiety regarding employment for those transitioning from the military. The Veterans' Employment Challenges study [27], released in August 2012, found that 2/3 of the generation identified finding a job as the greatest challenge they faced, and those with physical or mental health issues were twice as likely as others to say that they were not ready for the transition. In addition, more than half of that sample believed that they needed additional training or education in order to be prepared for the civilian workforce. It is likely that the majority of OIF/OEF/ONDera individuals with PMD are facing additional struggles with issues related to employment and vocational uncertainty.

VA has responded to the health care challenges posed by the complexity of OIF, OEF, and OND Veterans' health and community adjustment needs with a variety of innovative programs emphasizing integrated rehabilitation treatment. The remainder of this paper illuminates an interactive, stepped care approach to the treatment of PMD within the context of interdisciplinary chronic pain and behavioral health services. This continuum of integrated care has been implemented at a large, southeastern VA hospital. The programs comprising this model of care are identified, defined and summarized, and three case studies highlighting the importance of vocational goals as a primary stated outcome for each case are examined. 


\section{Chronic Pain Rehabilitation Program (CPRP)}

The CPRP is a 3-week, inpatient, interdisciplinary, chronic pain rehabilitation program established in 1988 to help veterans with chronic pain learn to cope more adaptively with their conditions. As the only program of its kind in the VA system, it is available to veterans and active duty service members nationwide. Program participants are typically highly focused on pain and its accompanying functional impairments. They have often had numerous unsuccessful pain treatments and experience negative emotions such as depression and/or anxiety. The CPRP focuses on increasing physical functioning and improving coping skills through a biopsychosocial approach to chronic pain with an emphasis on self-managed techniques. Decreasing reliance on medications and other passive modalities is also emphasized, as is the importance of taking an active role in one's own healthcare. The goal of the program is to improve functioning in all areas, including vocational, in order to improve overall quality of life. Those who participate in the inpatient CPRP have six to eight hours of treatment per day, which includes physical therapy, occupational therapy, pool therapy, recreational therapy, various educational groups, and consultation with Vocational Rehabilitation Services. Individualized goals are developed to meet the specific needs of each participant. Outcomes measures assessing the functional impact of chronic pain are conducted through self-report measures. For example, the Pain Outcomes Questionnaire (POQ) is administered along with other inventories that assess the presence and intensity of affective symptomology and coping styles at specified intervals during the treatment program and at follow-up. Results from these measures help determine treatment and discharge planning.

\section{Center for Post Deployment Health and Education (CPHE)}

The CPHE is an interdisciplinary, outpatient behavioral health program developed specifically to address PMD and its associated functional difficulties. The program was designed to challenge participants to actively and adaptively focus on functional improvement rather than diagnostic categorization. The goals of the program are to improve daily functioning, to manage chronic pain, to reduce stress and distress, to prevent worsening of symptoms, and to foster in- dependence. In so doing, CPHE provides treatment in multiple formats. First, treatment within CPHE includes cognitive behavioral psycho-educational groups and brief, problem-focused individual psychotherapy. Both modes of therapy are based upon conceptually similar psychopathological processes, such as cognitive distortions and the role of fear and avoidance. Second, psychiatric medication management is offered. Third, physical therapy is an integral component for pain rehabilitation and mood/self esteem enhancement. Fourth, vocational rehabilitation services are consulted as appropriate. As clinically indicated, CPHE participants also may complete evidence-based traumafocused intervention for PTSD while enrolled in the program (i.e., Prolonged Exposure Therapy) or they may be referred to other treatment programs concurrently, depending on clinical need. Similar to CPRP procedure, the POQ and appropriate affective symptom inventories are administered at the beginning of CPHE treatment, after completion of the introductory phase of treatment, and at treatment completion. Results from these measures factor into treatment and discharge planning.

\section{Vocational Rehabilitation Services}

As a matter of course for CPRP participants and as appropriate for CPHE participants, a Vocational Rehabilitation Specialist (VRS) is consulted for evaluation, vocational rehabilitation-focused case management, and vocational planning. An initial assessment is conducted to determine goals and to identify the need for further vocational training. Should training be a targeted goal, a comprehensive evaluation consisting of the following measures is completed: Career Exploration Inventory - Fourth Edition (CEI) [28], a self-review instrument of work, leisure, and learning; Career Scope [29] computer-based test, a measure of interest and aptitude; Shipley - Second Edition (Shipley-2) [30], an assessment of cognitive ability and impairment; Test of Adult Basic Education (TABE) [31], a measure of skills and knowledge. At the conclusion of testing, vocational exploration commences with the Occupational Network (O'Net) [32] or veterans may consult the Career Exploration Website Center. Individual job searches are encouraged to ascertain the market for specific fields of interest. In addition, research into required qualifications and avenues for pursuing those qualifications is emphasized. In some cases, work study or job shadowing may be 
suggested. Depending on stated individual goals, eligible educational benefits are reviewed (e.g., Post-9/11 GI Bill) as are other community services and veteranspecific retraining services (e.g., Veteran Retraining Assistance Program). For veterans whose emotional issues interfere with workforce re-entry, referral into VA's Compensated Work Therapy program (CWT) is offered. Finally, the VRS will emphasize the importance of realistic goal setting while providing a respectful, supportive atmosphere that normalizes any emotional responses related to transitioning to the civilian work environment.

\section{Case examples}

The following paragraphs summarize three case examples that demonstrate the need and importance of VRS as part of comprehensive treatment for veterans presenting with co-occurring pain and emotional difficulties.

\subsection{Case 1}

Mr. X is a 26-year-old, single, male, United States Army, OIF veteran who was referred to CPHE by the Post Deployment Clinic (PDC) for evaluation and treatment of combat-related PTSD, substance dependence, chronic bilateral knee pain, and chronic joint pain. PDC providers referred the veteran to VRS at the time of his referral to CPHE. Mr. X reported that his knee pain began in 2008 , likely related to overuse, and had worsened over time. He indicated his current and usual pain levels were 6 to 7 on a scale of 0 to 10 , with 0 being no pain and 10 being the worst pain imaginable. He reported pain-related difficulties in physical functioning, recreational activities, mood, sexual functioning, relationships, and quality of sleep. He reported combat-related traumas during his OIF tour which led to PTSD and depressive symptoms as well as substance-based coping. He reported situational stressors were contributing to his levels of psychological distress, citing work/vocational difficulties as primary. At the time of his evaluation with CPHE, he had been participating in a substance abuse recovery program with benefit. He acknowledged the need, however, to address more fully the fundamental anxiety issues underlying his substance use and maintaining his levels of distress/PTSD and appeared motivated to do so. He successfully completed CPHE programming with reported gains in mood, coping, and self-efficacy. Results from repeated administration of outcomes measures were consistent with self-reported functional gains. He completed recommended evaluation and treatment with the dual diagnosis program, which addressed anxiety and substance use disorders, and with the PTSD clinic during his course of treatment with CPHE and after its completion.

Concurrent with his behavioral health and mental health treatment, Mr. X followed consistently with the VRS as he was highly motivated to find employment. Due to the complexity of his emotional difficulties, the VRS recommended participation in CWT as well as maintaining his engagement in CPHE, PTSD clinic and dual diagnosis programming. During his CWT participation, the veteran continued to engage in appropriate behavioral/mental health services. With the assistance of the VRS, Mr. X secured an interview with a federal agency and the VRS assisted with performance-based interview preparation as well as additional strategies to facilitate interview success. The veteran was offered and accepted the position for which he interviewed, and he continues to consult with the VRS for work adjustment counseling as needed.

\subsection{Case 2}

Ms. Y is a 33-year-old, divorced, female, United States Marine Corps veteran who was referred to CPRP by the VRS for evaluation and treatment of chronic low back pain with related mood issues and impairment in daily activities. During screening for the CPRP, Ms. Y reported that her back pain began following a military training-related fall. She reported that her current and usual levels of pain were a 6 to 7 on a 0 to 10 scale, with 0 being no pain and 10 being the worst pain imaginable. She reported pain-related impairment in multiple areas of her life including mobility, sleep, mood, and physical and recreational functioning. Ms. $\mathrm{Y}$ had previous pain treatment with limited benefit including two surgeries, injections, and acupuncture. At the time of program admission, she was taking $10 \mathrm{mg}$ of oxycodone three times daily, which was a reduction from her use in previous years. She was motivated to discontinue opioid analgesics as a part of "taking [her] life back." Her individual program objectives were to achieve her career goals and eventually become a mother without being dependent on medications to manage her pain.

At the time of admission, Ms. Y had a Bachelor's degree in social work. While she was hoping to pursue her Master's degree, she was uncertain about her 
ability to engage in a full-time school program or career, and was contemplating Social Security Disability Insurance. She met with the CPRP VRS on several occasions while in the program. Initially, the qualifications needed to become a licensed social worker were explored. With the support of the VRS, Ms. Y contacted several universities and made plans to take the Graduate Record Examination. The assistance of the VRS along with the acquisition of improved skills for pain management in the CPRP allowed Ms. Y to be discharged from the program with confidence regarding her future. Results from the repeated administration of outcomes measures were consistent with her self-reported functional gains.

Ms. Y has contacted the CPRP VRS at multiple points since her program discharge, receiving motivational and supportive counseling as needed. Eighteen months after program completion, she completed her Master's of Social Work and currently is employed full-time as a hospice care team member. She reports satisfaction with her vocational choice. In addition, she is engaged to be married to a fellow veteran with the hope of achieving her other program goal of starting a family. She continues to implement the tools learned while in the CPRP and has acted on the guidance provided by the VRS.

\subsection{Case 3}

Mr. Z is a 28-year-old, single, male, United States Army veteran who was referred for CPHE evaluation and treatment by the PDC to address mood and anxiety problems, military-to-civilian adjustment challenges, primary chronic left hip pain, and secondary ankle and headache pain. He reported that his current and usual pain levels were 4 to 6 on a 0 to 10 scale, with 0 being no pain and 10 being the worst pain imaginable. He acknowledged pain-related difficulty in multiple areas of life, including sleep, mood, and sexual, physical and recreational functioning. Despite benefiting from exercise and physical therapy, he reported ongoing painrelated difficulties and expressed a desire to develop additional pain management strategies. Mr. Z served as an officer in the Army and a primary stressor in his transition to the civilian sector was vocational. He indicated a specific concern regarding whether he should seek employment or pursue additional education. He reported anxiety related to this decision as well as anxiety and irritable mood stemming from difficulties in his adjustment to civilian life and to factors associated with his deployment.
Mr. Z was referred for VRS evaluation, testing, and career counseling. Upon initial assessment with the VRS, a plan was implemented to facilitate confidencebuilding coupled with continued engagement in the CPHE to address his pain and mood problems. Exploratory decision-making was conducted and vocational exploration and testing were completed (CEI-4 $4^{\text {th }}$ Edition; Shipley-2; Career Scope; TABE). The VRS normalized the inherent stress in transitioning from the military to the civilian sector, and the veteran was encouraged to consistently implement stress, mood, and pain management strategies learned in CPHE to increase the chances of personal and professional success. He applied for a second undergraduate degree and was encouraged to maintain job searches to stay abreast of opportunities in his chosen field. Mr. Z was accepted into an undergraduate program as a dual major student, and reported satisfaction and excitement at the opportunity to pursue this goal en route to his career in the area of international studies/business/economics. Recently, Mr. Z successfully completed CPHE programming with reported benefits in his mood and anxiety levels, interpersonal communication skills, self-view, and pain symptoms. Results from repeated administration of outcomes measures were consistent with Mr. Z's functional gains.

\section{Summary}

PMD may be conceptualized as a multidimensional, clinical phenomenon reflecting overlapping symptomology, far-reaching functional impact, and considerable influence on quality of life. PMD treatment must mirror this complexity in its thoroughness and innovation from a veteran's entry point into VA care onward via referral to existing interdisciplinary programs such as CPRP. Furthermore, the development of PMD-specific behavioral health programming such as CPHE is critical for the effective treatment of cooccurring conditions. Programs and services emphasizing the transition from the military to civilian sectors are needed for successful community reintegration. Coordinating outreach and communication between and the Department of Defense must be appreciated and enhanced. For many OIF/OEF/OND returnees, difficulties navigating the civilian vocational world present an additional layer of complexity and frustration upon the influence of PMD on daily life and sense of self. The three case examples show how vocational rehabilitation services, as a matter of course or as an adjunct to behavioral health care, are an integral component of PMD treatment. 


\section{References}

[1] Helmer DA, Chandler HK, Quigley KS, Blatt M, Teichman R, Gudrun L. Chronic widespread pain, mental health, and physical role function in $\mathrm{OEF} / \mathrm{OIF}$ veterans. Pain Medicine, 2009; 10(7): 1174.

[2] Gatchel RJ. Comorbidity of chronic pain and mental health disorders: The biopsychosocial perspective. American Psychologist, 2004; 59(8): 795.

[3] Asmundson GJG, Katz J. Understanding the co-occurrence of anxiety disorders and chronic pain: State of the art. Depression and Anxiety, 2009; 26: 888.

[4] Clark ME, Walker RL, Gironda RJ, \& Scholten JD. Comparison of pain and emotional symptoms in soldiers with polytrauma: Unique aspects of blast exposure. Pain Medicine, 2009; 10(3): 447.

[5] Lumley MA, Stout RL, Cohen JL, Neely LC, Sander LM, Burger AJ. An emotional exposure-based treatment of traumatic stress for people with chronic pain: Preliminar y results for fibromyalgia syndrome. Psychotherapy Theory, Research, Practice, Training, 2008; 45(2): 165.

[6] Villano CL, Rosenblum A, Magura S, Fong C, Cleland C, Betzler TF. Prevalence and correlates of posttraumatic stress disorder and chronic severe pain in psychiatric outpatients. Journal of Rehabilitation Research and Development, 2007; 44(2): 167.

[7] DeCarvalho LT, Whealin JM. What pain specialists need to know about posttraumatic stress disorder in Operation Iraqi Freedom and Operation Enduring Freedom returnees. Journal of Musculoskeletal Pain, 2006; 14(3): 37.

[8] Otis JD, Keane TM, Kerns RD. An examination of the relationship between chronic pain and posttraumatic stress disorder. Journal of Rehabilitation Research and Development, 2003; 40(5): 397.

[9] Otis JD, Keane TM, Kerns RD, Monson C, Scioli E. The development of an integrated treatment for veterans with comorbid chronic pain and posttraumatic stress disorder. Pain Medicine, 2009; 10(7): 1300.

[10] Shipherd JC, Beck JG, Hamblen JL, Lackner JM, Freeman JB. A preliminary examination of treatment for posttraumatic stress disorder in chronic pain patients: A case study. Journal of Traumatic Stress, 2003; 16(5): 451.

[11] Shipherd JC, Keyes M, Jovanovic T, Read DJ, Baltzell D, Worley V, Gordon-Brown V, Hayslett C, Duncan E. Veterans seeking treatment for posttraumatic stress disorder: What about comorbid chronic pain? Journal of Rehabilitation Research and Development, 2007; 44(2): 153.

[12] Lew HL, Otis JD, Tun C, Kerns RD, Clark ME, Cifu DX. Prevalence of chronic pain, posttraumatic stress disorder, and persistent postconcussive symptoms in OIF/OEF veterans: Polytrauma clinical triad. Journal of Rehabilitation Research and Development, 2009; 46(6): 697.

[13] Clark ME. Post-deployment pain: A need for rapid detection and intervention. Pain Medicine, 2004; 5: 333.

[14] Gironda RJ, Clark ME, Massengale JP, Walker RL. Pain among veterans of Operations Enduring Freedom and Iraqi Freedom. Pain Medicine, 2006; 7(4): 339.

[15] Clark ME, Bair MJ, Buckenmaier III CC, Gironda RJ, Walker RL. Pain and combat injuries in soldiers returning from Operations Enduring Freedom and Iraqi Freedom: Implications for research and practice. Journal of Rehabilitation Research and Development, 2007; 44(2): 179.

[16] Walker RL, Clark ME, Sanders SH. The "Post-Deployment Multi-Symptom Disorder": An emerging syndrome in need of a new treatment paradigm. Psychological Services, 2010.

[17] Clark ME, Scholten JD, Walker RL, Gironda RJ. Assessment and treatment of pain associated with combat-related polytrauma. Pain Medicine, 2009; 10(3): 456.

[18] Mersky H, Bogduk H. Classification of chronic pain: Descriptions of chronic pain syndromes and definitions of pain terms. In Mersky $\mathrm{H}$, Bogduk $\mathrm{H}$, editors. International Association for the Study of Pain Task-Force on Taxonomy. Seattle: IASP Press, 1994.

[19] Sanders SH, Harden RN, Vicente PJ. Evidence-based clinical practice guidelines for interdisciplinary rehabilitation of chronic nonmalignant pain syndrome patients. Pain Practice, 2005; 5(4): 303.

[20] Gatchel RJ, Peng YB, Fuchs PN, Peters ML, Turk DC. The biopsychosocial approach to chronic pain: Scientific advances and future directions. Psychological Bulletin, 2007; 133(4): 581.

[21] American Psychiatric Association. Diagnostic and Statistical Manual of Mental Disorders - Fourth Edition, Text Revision. Washington DC: APA; 2000.

[22] Hoge CW, Terhakopian A, Castro CA, Messer SC, Engle CC. Association of posttraumatic stress disorder with somatic symptoms, health care visits, and absenteeism among Iraq war veterans. American Journal of Psychiatry, 2007; 164: 150.

[23] Asmundson GJG, Coons MJ, Taylor S, Katz J. PTSD and the experience of pain: Research and clinical implications of shared vulnerability and mutual maintenance models. Canadian Journal of Psychiatry, 2002; 47: 930.

[24] Kessler RC. Posttraumatic stress disorder: The burden to the individual and to society. Journal of Clinical Psychiatry, 2002; 61(suppl 5): 4-12.

[25] Veteran Unemployment Rate Falls to 6.3 Percent in October; At 10 Percent for Post-9/11 Vets November 2, 2012 by Lauren Bailey, Vantage [Internet] [cited 2013 Jan 4]. Available at http://www.blogs.va.gov/VAntage/8311/veteranunemployment-rate-falls-to-6-3-percent-in-october-at-10percent-for-post-911-vets/.

[26] Various IAVA pages [Internet] [cited 2013 Jan 4]. Available at http://iava.org/blog/unemployment-among-new-veterans-rem ains-higher-average-97.

[27] Veterans' Employment Challenges Study - survey results [Internet] [cited 2013 Jan 4]. Available at http://www.prudential. com/documents/public/VeteransEmploymentChallenges.pdf.

[28] Liptak J. Career Exploration Inventory $-4^{\text {th }}$ Edition. Indianapolis: JIST, 2010.

[29] Career Scope [Internet] [cited 2012 Dec 21]. Available at http://www.vri.org/products/careerscope-v10/benefits.

[30] Shipley WC, Gruber CP, Martin TA, Klein AM. Shipley Institute of Living Scale - Second Edition. Torrance, CA: Western Psychological Services, 2009.

[31] Test of Adult Basic Education [Internet] [cited 2012 Dec 21]. Available at http://www.ctb.com/ctb.com/control/product FamilyViewAction?productFamilyId $=608 \& \mathrm{p}=$ products.

[32] Occupational Network [Internet] [cited 2012 Dec 21]. Available at http://www.onetonline.org. 